\title{
INVESTIGATION OF AMPLITUDE-FREQUENCY CHARACTERISTICS OF DISTURBING AND CONTROL IMPACTS OF ASYMMETRIC SWATH HEADER MACHINE-AND- TRACTOR AGGREGATE
}

\author{
Volodymyr Bulgakov ${ }^{1}$, Anatoliy Zaryshnyak ${ }^{2}$, Hristo Beloev ${ }^{3}$, Semjons Ivanovs ${ }^{4}$ \\ ${ }^{1}$ National University of Life and Environmental Sciences of Ukraine, Ukraine; \\ ${ }^{2}$ National Academy of Agrarian Sciences of Ukraine, Ukraine; \\ 3“Angel Kanchev" University of Rousse, Bulgaria; \\ ${ }^{4}$ Latvia University of Life Sciences and Technologies, Latvia \\ semjons@apollo.lv
}

\begin{abstract}
The dynamics of the movement of an asymmetric machine-and-tractor aggregate has essential peculiarities because of the presence of an asymmetric load and a constant disturbing and control impact upon the elements that control its movement. The experimental amplitude-frequency characteristics were studied under field conditions using as a model a harvesting asymmetric machine-and-tractor aggregate composed from a wheeled aggregating tractor MTZ-82 and a trailed swath header (windrower) ZVP-6, which performs the technological process of collecting winter wheat into swaths. Normalized spectral densities of variations of the turning angle of the trailed swath header have been determined, as well as the turning angle of the driven wheels of the aggregating tractor and relative tractor bearing.
\end{abstract}

Keywords: spectral density, variations of the turning angle.

\section{Introduction}

Due to the peculiarities of the performed technological process some agricultural machines (for example, swaths headers (windrowers), mowers, ploughs, etc.) have an asymmetric arrangement relative to the longitudinal axis of the tractor [1].

The dynamics of the movement of such an aggregate has essential peculiarities because of the presence of an asymmetric load and a constant disturbing and control impact upon the elements that control its movement $[1 ; 2]$. The line of action of the equivalent forces of resistance to the movement does not coincide with the longitudinal vertical plane of symmetry of the tractor, which causes the appearance of lateral forces on the tractor wheels, leading to lateral deviation of the latter and violation of the straight path of the movement. To maintain a straight path of the machine-and-tractor aggregate, it is necessary to install the driving wheels of the tractor at some angle to the longitudinal axis of symmetry of the tractor or to correct constantly their direction [3-5]. In addition, in order to achieve the desired performance, an optimum speed should be maintained.

There are a number of works devoted to the studies of the dynamics of asymmetric machine-andtractor aggregates, yet they do not give a complete assessment of the influence of certain parameters or operating modes, and detailed studies are required for specific types of machines.

Many researchers are convinced that, when studying the transformation of stationary random processes by linear control systems, the spectral density (the Fourier transform by the correlation function) is the most convenient characteristic [6;7].

In our previous work [8] theoretical studies of the plane-parallel motion of an asymmetric swath header (windrowing) machine-and-tractor aggregate were carried out.

The purpose of this work was to determine normalised spectral densities of variations of the turning angle of a trailed swath header, the turning angle of the driven wheels of the aggregating tractor and the relative bearing of the tractor, while operating in an aggregate with a the trailed swath header, as well as to compare them with the earlier obtained theoretical data.

\section{Materials and methods}

The experimental amplitude-frequency characteristics were studied under field conditions using as a model a harvesting asymmetric machine-and-tractor aggregate composed from a wheeled aggregating tractor MTZ-82 and a trailed swath header ZVP-6, which performs the technological process of collecting winter wheat into swaths (Fig. 1). In our studies, the MTZ tractor is chosen because it best fits (by all characteristics) for the work with the ZVP-6 swathing harvester. But any other wheeled tractor with the mass and dimension characteristics the same as MTZ-82, (i.e., of the 
traction class $14 \mathrm{kN}$ ), would operate under the field conditions with the same trailed swathing harvester in a similar way as described in our article. The experimental studies were carried out under field conditions at the following agricultural background: at a depth of up to $15 \mathrm{~cm}$ the soil moisture was $10-14 \%$, the soil hardness was $2.3 \mathrm{mPa}$, the density of the wheat plants was 496 pieces. $\mathrm{m}^{-2}$, the plant height $-0.86 \mathrm{~m}$. A block diagram of the measuring and registration complex for the experimental study of the parameters of an asymmetric machine-and-tractor aggregate is given in Fig. 2.

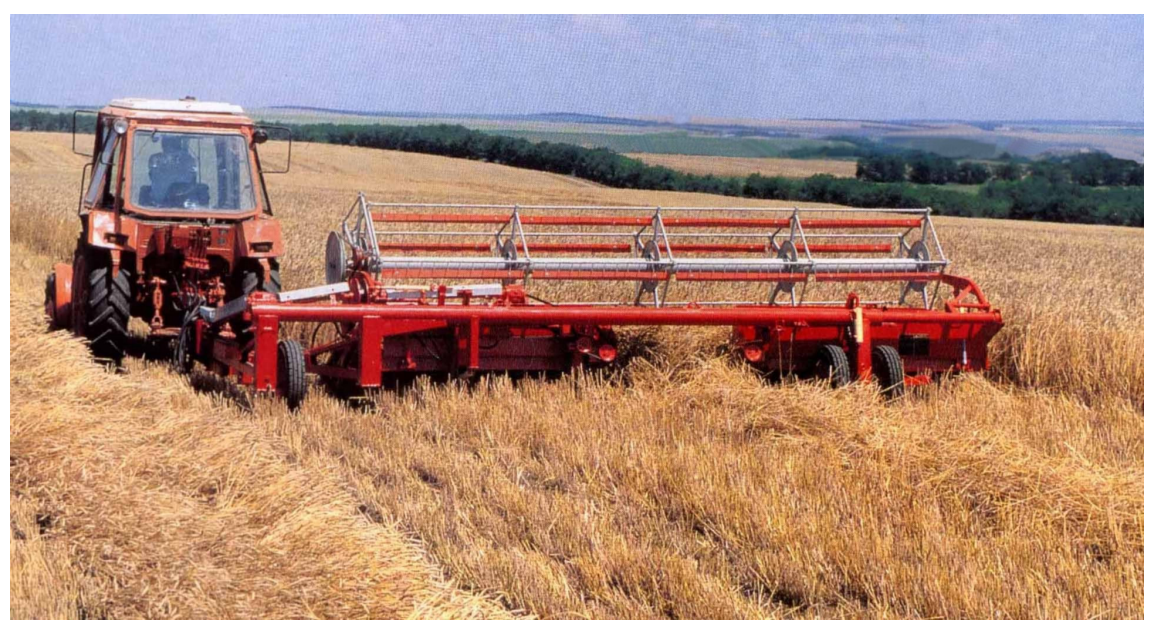

Fig. 1. Asymmetric swath header ZVP-6 machine-and-tractor aggregate during field experimental research

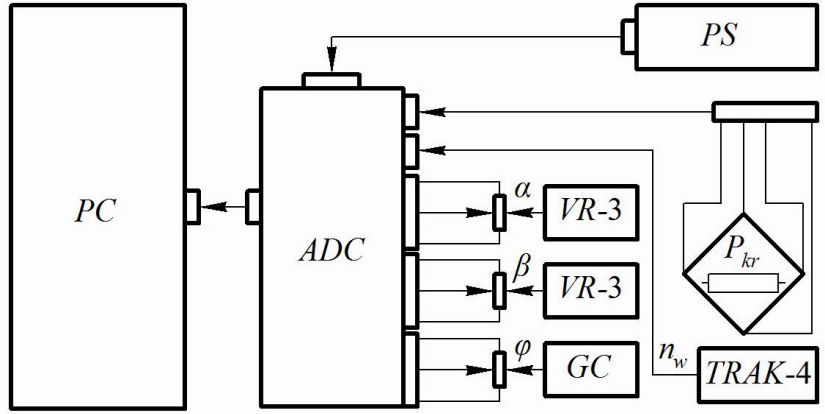

Fig. 2. Block diagram of measuring and registration complex for experimental study of dynamics of asymmetric machine-and-tractor aggregate: $\mathrm{PC}$ - personal computer;

ADC -analogue-to-digital converter; PS - power supply; $P_{k r}$ - tensometric bridge;

VR-3 - variable resistance $470 \mathrm{Ohm}$; GC - hydraulic semi-compass; GC-52;

TRAK-4 - mercury-amalgated current collector; $\alpha$ - turning angle of the tractor driven wheels; $\beta$ - turning angle of the trailed swath header; $\varphi$ - relative bearing of the aggregating tractor; $n_{w}$ - turns of the track measuring wheel

During the operative movement of the swath header, through the analogue-to-digital converter there were synchronically recorded on the PC: the relative bearing of the aggregating tractor $(\varphi)$; the turning angle of the driven wheels of the aggregating tractor $(\alpha)$; the tractive resistance of the swath $\left(P_{k r}\right)$; the turning angle of the swath header $(\beta)$ in a horizontal plane.

From the obtained realisations for values $\varphi, \alpha$ and $\beta$, such statistical characteristics were determined as the mean square deviations $\left(\sigma_{i}\right)$ and normalised spectral densities $\left(S_{i}\right)$. The tractive resistance of the swath header $\left(P_{k r}\right)$ was estimated only by the average value, used for further calculations.

The experimental amplitude-frequency characteristics of the swath header machine-and-tractor aggregate were calculated from expression $[9 ; 10]$ : 


$$
A(\omega)=\frac{\sigma_{y}}{\sigma_{x}} \sqrt{\frac{S_{y}}{S_{x}}},
$$

where $\sigma_{x}, S_{x}$ - mean square deviation and the normalised spectral density of the input value $(\alpha$ or $\beta)$;

$\sigma_{y}, S_{y}$ - mean square deviation and the normalised spectral density of the output value $(\varphi)$; $\omega$ - frequency of variations of the control and the disturbing impact.

The theoretical amplitude-frequency characteristics for the same swath header asymmetric machine-and-tractor aggregate were calculated on the PC using the transfer functions $W_{1}(S)$ and $W_{0}(S)$, derived from the mathematical models we have constructed [8]. The drag coefficients for the tires of the front $\left(k_{A}\right)$ and the rear $\left(k_{B}\right)$ wheels of the aggregating tractor, as well as the left $\left(k_{1}\right)$ and the two right $\left(k_{2}\right)$ supporting wheels of the trailed swath header were calculated according to the formula by R. Smiley and V. Horn [6]. The value of the rolling resistance $\left(P_{f a}\right)$ of the front axle of the wheeled aggregating tractor was found from the following expression:

$$
P_{f a}=f \cdot N_{a},
$$

where $f$ - coefficient of rolling resistance (in the analytical calculations for the background "stubble" one can take the value of this coefficient, equal to $f=0.1$ );

$N_{a}$ - vertical load on the front axle of the driven wheels of the aggregating wheel tractor.

According to the same formula the rolling resistance of the trailed swath header is also determined, which will be equal to:

$$
P_{f m}=f \cdot g\left(M_{1}+M_{2}\right),
$$

where $M_{1}$ and $M_{2}-$ masses, correspondingly, for one left-side and two right-side supporting wheels (determined by weighing the swathing harvester on the electronic scale FS608D).

Having calculated the value of the rolling resistance of the swath header, the resistance created by the stem massif $\left(R_{z}\right)$ according to expression (3) was calculated, when it was mowed and transported into a swath:

$$
R_{2}=P_{\kappa p}-P_{f m} .
$$

The speed of movement of the swath header machine-and-tractor aggregate was determined directly on the field by means of the travel-measuring wheel. The design parameters of the examined swath header machine-and-tractor aggregate: $M_{T}, J_{S}, L, a_{T}, J_{C}, a_{M}, l, b, d_{M}, h$, which are required to calculate coefficients $A_{11}-A_{36}, f_{11}$ and $f_{21}$, and which are included into the transfer functions $W_{1}(S)$ and $W_{0}(S)$, were determined according to the methodology set forth in Standard [11]. During the experimental studies the asymmetric swath header machine-and-tractor aggregate was moving at a speed of $2.45 \mathrm{~m} \cdot \mathrm{s}^{-1}\left(8.82 \mathrm{~km} \cdot \mathrm{h}^{-1}\right)$. The left and the two right supporting wheels of the ZVP-6 swath header were set at zero turning angles in a horizontal plane (i.e., $\alpha_{1}=\alpha_{2}=0$ ), the left supporting wheel of the swath header being installed without a vertical additional loading and offset in a transverse direction.

\section{Results and discussion}

In the course of the research it was established that the average value of the tractive resistance of the swath header $\left(P_{k r}\right)$ ZVP-6 swath header was $8.5 \mathrm{kN}$, and the rolling resistance force $\left(P_{f m}\right)$ was $1.5 \mathrm{kN}$. Hence it follows that the resistance force created by the stem massif $\left(R_{z}\right)$ cut by the swath header was equal to $7.0 \mathrm{kN}$.

According to the applied program numerical calculations of the obtained experimental data were carried out on the PC. The resulting normalised spectral densities of the disturbance impact (Fig. 3) and the control impact (Fig. 4) indicate a relatively low spectrum of variations, both of the turning angle $(\beta)$ of the swath header and the turning angle $(\alpha)$ of the driven wheels of the aggregating tractor. 


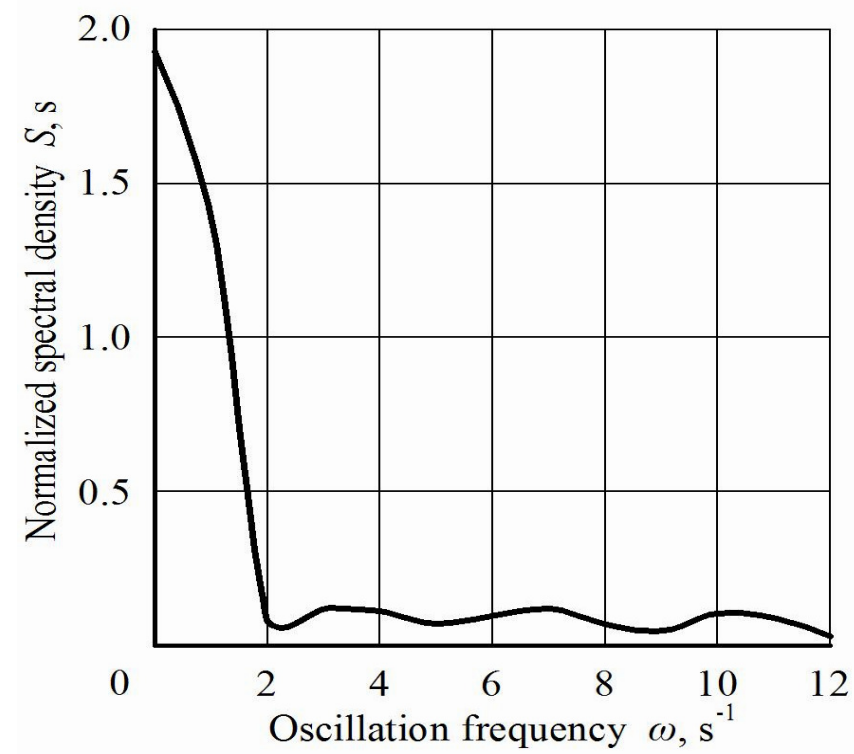

Fig. 3. Normalised spectral density of variations of turning angle $\beta$ of trailed swath header

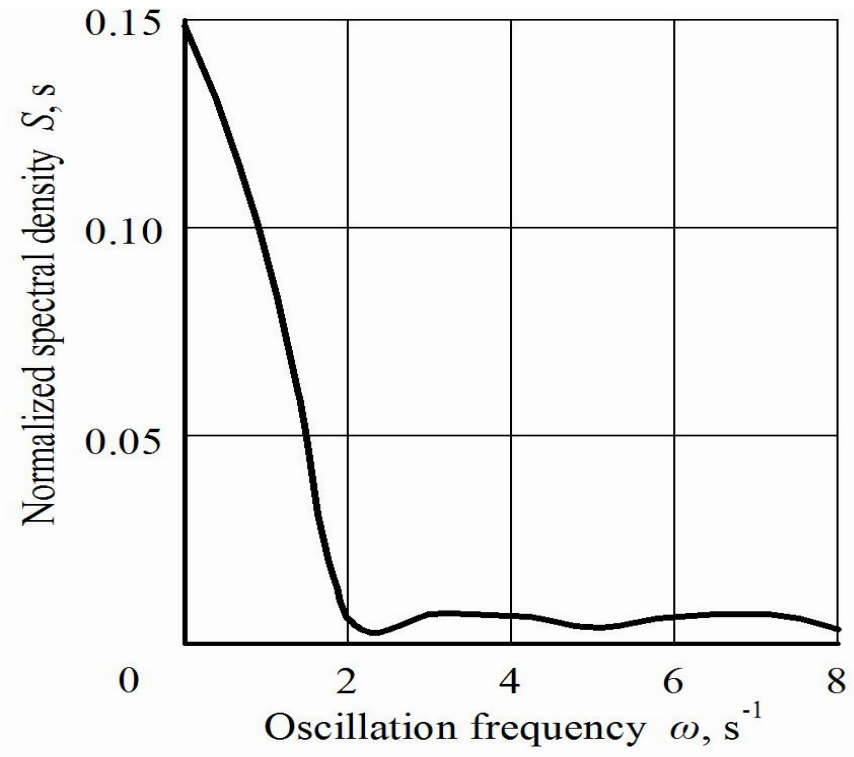

Fig. 4. Normalised spectral density of variations of turning angle $\alpha$ of driven wheels of aggregating tractor

Accordingly low was also the spectrum of variations of the relative bearing $\varphi$ of the source of energy (Fig. 5). The main dispersion spectrum of this parameter under the experimental conditions is concentrated in the frequency range $0-2 \mathrm{~s}^{-1}$ or $0-0.3 \mathrm{~Hz}$. The experimental amplitude-frequency characteristics are presented in Fig. 6. The design parameters of the asymmetric swath header machine-and-tractor aggregate, required in order to calculate the theoretical amplitude-frequency characteristics, were the following: $M_{T}=3700 \mathrm{~kg}, J_{S}=3.0 \mathrm{kN} \cdot \mathrm{m} \cdot \mathrm{s}^{2}, L=2.37 \mathrm{~m}, a_{T}=0.96 \mathrm{~m}, J_{C}=$ $7.0 \mathrm{kN} \cdot \mathrm{m} \cdot \mathrm{s}^{2}, a_{M}=1.05 \mathrm{~m}, l=3.4 \mathrm{~m}, b=6.1 \mathrm{~m}, d_{M}=1.3 \mathrm{~m}, h=0.2 \mathrm{~m}, k_{A}=81.0 \mathrm{kN} \cdot \mathrm{rad}^{-1}, k_{B}=$ $125.0 \mathrm{kN} \cdot \mathrm{rad}^{-1}, k_{1}=30.0 \mathrm{kN} \cdot \mathrm{rad}^{-1}, k_{2}=85.0 \mathrm{kN} \cdot \mathrm{rad}^{-1}$.

The spectral density of variations of the turning angle of the trailed swath header (Fig. 3.) ought to be close in shape (but not identical) with the spectral density of variations of the turning angle of the driven wheels of the aggregating tractor (Fig. 5).

Analysis of the obtained data showed that in case the asymmetric swath header machine-andtractor aggregate, as a dynamic system, perceives the disturbing (Fig. 6, Curves a) and the control (Fig. 6, Curves b) impacts, the maximum discrepancy between the theoretical and experimental amplitude-frequency characteristics does not exceed $8 \%$. Such a coincidence of experimental and 
calculated data points to the adequacy of the developed mathematical model [8], which gives the right to use it for a reliable justification of the scheme and the design parameters of the asymmetric swath header machine-and-tractor aggregate.

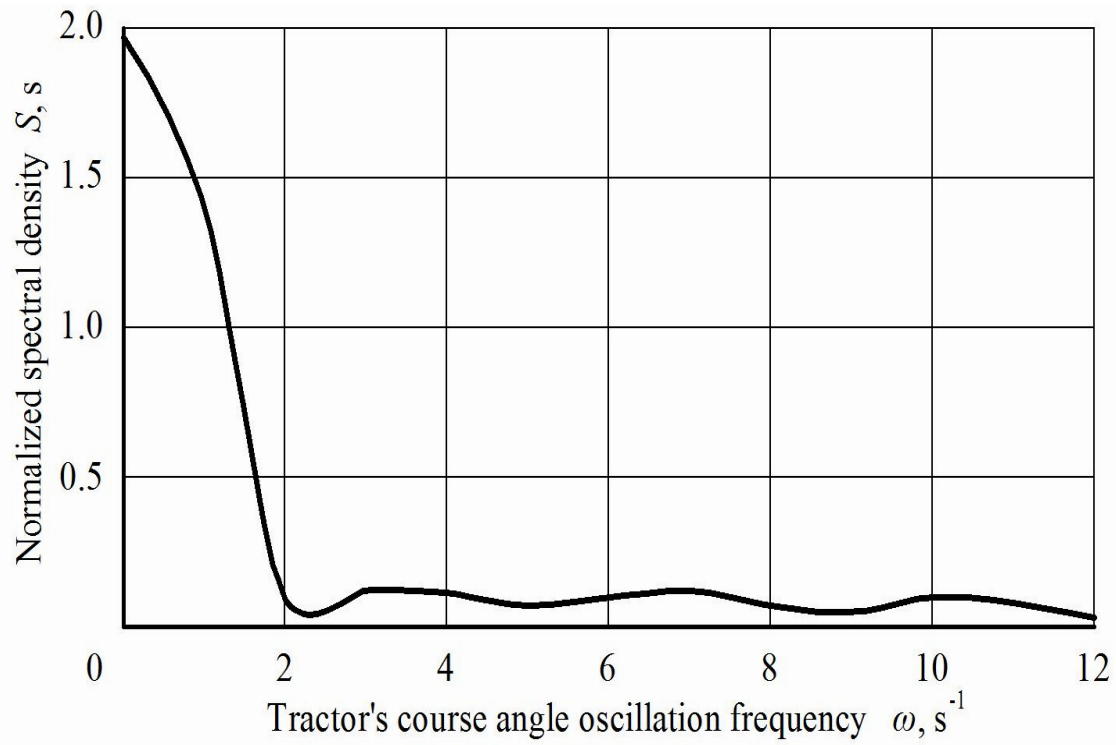

Fig. 5. Normalised spectral density of variations of relative bearing $\varphi$ of tractor during its operation in aggregate with trailed swath header

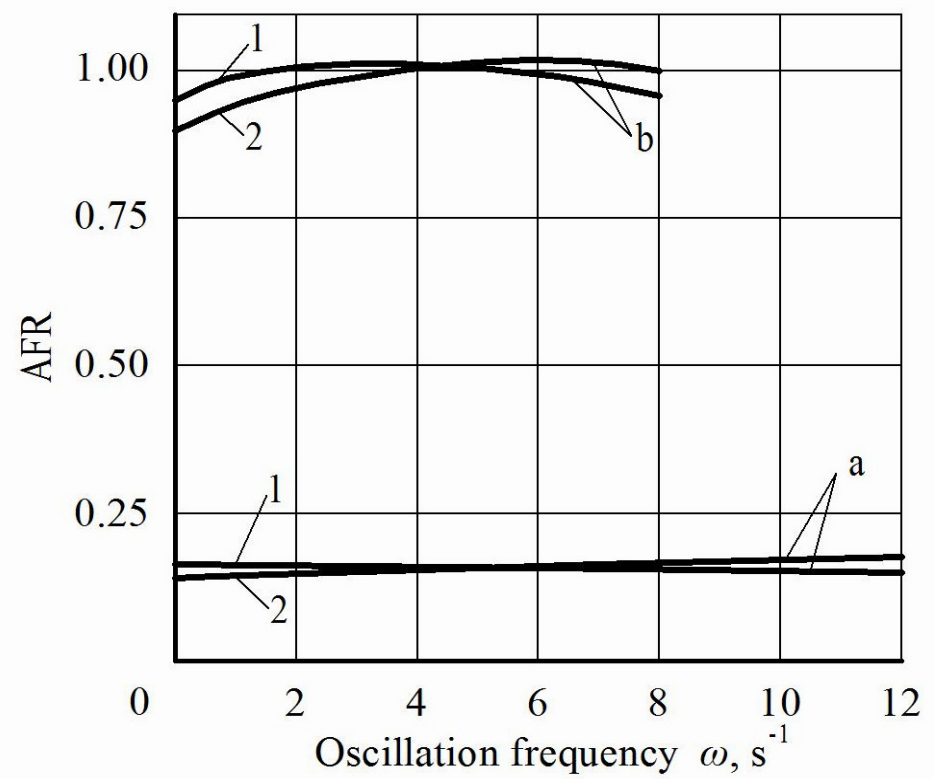

Fig. 6. Theoretical (1) and experimental (2) amplitude-frequency characteristics of relative bearing $\varphi$ of tractor when it perceives disturbances in form of variations in turning angle of the swath header (a) and control impact in form of variations in turning angle of driven wheels of tractor $(b)$

It is known [6] that, when a dynamic system perceives one or another disturbance, the desired amplitude-frequency characteristic has to be as small as possible. In an ideal case it must be equal to zero. At the same time the phase-frequency shift (i.e., the delay in the reaction of the system) has to be as large as possible. In case the dynamic system perceives a disturbance, the desired amplitudefrequency characteristics should be equal to 0 , the phase-frequency characteristics, on the contrary, tend to $\infty$. Those parameters and operating modes of the aggregate are optimal that in the operating 
range of frequencies of variations of the control and the disturbing input impacts maximally approximate the actual amplitude-frequency and phase-frequency characteristics to the desired ones.

Analysis of spectral characteristics showed that the used aggregating wheeled tractor of the traction class $14 \mathrm{kN}$ reproduces fluctuations of the turning angle $\beta$ of the trailed swathing harvester with practically the same amplitude (i.e. dispersion) and frequency. To maintain controlled movement of this asymmetric harvesting machine-and-tractor aggregate, this requires about 10 times lesser dispersion of the fluctuations of angle $\alpha$ of its driven wheels. It is possible to reduce the dispersion of the fluctuations of this parameter further by automating the control process of the asymmetric harvesting aggregate by means of a GPS system equipped with an automatic system of impact upon the steering wheel of the aggregating tractor.

\section{Conclusions}

There are determined normalised spectral densities of variations of the turning angle $\beta$ of the trailed swath header, the turning angle $\alpha$ of the driven wheels of the aggregating tractor, and the relative bearing $\varphi$ of the tractor during its operation in the aggregate with a trailed swath header.

In case the asymmetric swath header machine-and-tractor aggregate, as a dynamic system, perceives a disturbing and control impacts, the maximum discrepancy between the theoretical and the experimental amplitude-frequency characteristics does not exceed $8 \%$, which points to the adequacy of the applied mathematical model for reliable substantiation of the scheme and the design parameters of the asymmetric swath header machine-and-tractor aggregate.

The expounded methodology may be applied to substantiate the scheme and the parameters of any machine-tractor aggregate in case it perceives external control and disturbing impacts.

\section{References}

[1] Гячев Л. О прямолинейном движении колесного трактора при боковом расположении навесной жатки (About rectilinear movement of a wheeled tractor with a laterally mounted reape) Mechanization and electrification of agriculture, No 6, 1979, pp. 40-42.

[2] Василенко П. Введение в земледельческую механику. (Introduction to agricultural mechanics). Agricultural Education, Kyiv, 1996. 294 p. (In Ukrainian)

[3] Nadykto V., Kyurchev V., Semenuk V., Nazin A. Harvesting of cereals separately. Zaporozhye: Inter-M, 2012. $132 \mathrm{p}$.

[4] Гуськов В. Тракторы: Теория (Tractors: Theory). Moskow, 1988. 376 p.

[5] Гячев Л. Устойчивость движения сельскохозяйственных машин и агрегатов (Stability of the movement of agricultural machines and aggregates). Moscow, 1981, 206 p. (In Russian)

[6] Wiggins S. Introduction to Applied Nonlinear Dynamical Systems and Chaos (2 ed.). New York: Springer Verlag, 2003. ISBN 0-387-00177-8.

[7] Bhatia N.P. Szegő, G.P. Stability theory of dynamical systems. Springer. 2002. ISBN 978-3-54042748-3

[8] Bulgakov V., Pascuzzi S., Nadykto V. and Ivanovs S. A Mathematical model of the plane-parallel movement of an asymmetric machine and tractor aggregate. Journal of Agricultural Engineering. Vol. 49, No 1, 2018, pp. 258-271. (In the Press)

[9] Smith M., Wisten M. A continuous day-to-day traffic assignment model and the existence of a continuous dynamic user equilibrium. Annals of Operations Research, 60 (1), 1995, pp. 59-79.

[10] Меркин Д.Р. Введение в теорию устойчивости движения. (Introduction to the stability theory of movement). Nauka, Moscow, 1976, 576 p. (In Russian)

[11] Standard: DSTU GOST 7057-2003. Agricultural tractors. Test methods. Kiev, 2003, 13 p. (In Ukrainian). 